\title{
Z. Lawrynowicz *
}

University of Science and Technology UTP, Mechanical Engineering Faculty, Department of Materials Science and Engineering, Av. Kaliskiego 7, 85-796 Bydgoszcz, Poland

*lawry@utp.edu.pl

\section{EFFECT OF THE DEGREE OF COLD WORK AND SENSITIZATION TIME ON INTERGRANULAR CORROSION BEHAVIOR IN AUSTENITIC STAINLESS STEEL}

\begin{abstract}
Present paper deals with the influence of a wide range of cold rolling (5, 10, 15 and maximum $40 \%$ cold deformation) and the sensitization time (aging at $700^{\circ} \mathrm{C}$ for $0.12,0.5,1,4,16$ and 32 hours) on intergranular corrosion (IGC). Intergranular corrosion of commercial stainless steel type X6CrNiTi18-10 (1.4541, AISI 321) is frequently observed in several process environments. These localized attacks are normally attributed to the carbide precipitation and concomitant depletion of chromium near grain boundary due to steel exposure to sensitization temperature. Such undesirable microchemistry is expected to be changed further if the material undergoes deformation prior to sensitization. The consequences of deformation on IGC have been investigated by using EN ISO 3651-1methods (Huey test - Corrosion test in nitric acid medium by measurement of loss in mass). Introducing deformation to the investigated stainless steel seems to change the kinetics of carbide precipitation $\mathrm{M}_{23} \mathrm{C}_{6}$ and thereby changes it resistance to IGC. Cold deformation before sensitization reduces the intensity of intergranular corrosion of this steel. The deformed structure created during the cold work process, numerous slip planes and the twins boundaries are just like the grain boundaries and the places where the chromium carbides preferentially precipitates. Due to the more evenly occurring precipitation processes within the whole deformed grains, there is no phenomenon of local grain boundary carbide precipitation, and thus there is no decrease in the resistance of this steel to intergranular corrosion. The assessment of the degree of intergranular corrosion was based on the measurement of mass loss and observation of corroded surfaces on optical and electron transmission and scanning microscopes.
\end{abstract}

Keywords: intergranular corrosion; cold deformation and the sensitization time; Huey test

\section{INTRODUCTION}

It knows that the most important corrosion forms in case of austenitic steels is the intergranular and the stress corrosion. The well known susceptibility of austenitic stainless steels to intergranular corrosion after heat treatment in the temperature range of $500^{\circ}-800^{\circ} \mathrm{C}$ (sensitization) has long been attributed to depletion of $\mathrm{Cr}$ from regions of the alloy matrix adjacent to grain boundaries in which $\mathrm{Cr}_{23} \mathrm{C}_{6}$ had precipitated. Those regions of the steel in which the local $\mathrm{Cr}$ composition falls below about $12 \%$ have a diminished ability to form a passive film and hence corrode preferentially [1] (Fig. 1). 
Stainless steels are common material of construction as these offer a wide range of corrosion resistance along with good fabrication and mechanical properties to many industrial environments. At the same time, these alloys are prone to microstructural changes along with changes in chemistry when exposed to sensitization temperatures possibly due to faulty heat treatment or welding operation. In the case of stainless steels, precipitation of chromium carbides takes place along the grain boundary region in the temperature range of $580-815^{\circ} \mathrm{C}$. This results in chromium depletion near the grain boundary and makes the region more susceptible to corrosion attack [2]. In certain environments, sensitized steels corrode preferentially along the grain boundary leaving the matrix unattacked, termed as intergranular corrosion. This causes frequent catastrophic failure of engineering components.

The stainless steel X6CrNiTi18-10 (1.4541, AISI 321) is a general purpose austenitic stainless steel with a face centred cubic structure. It is essentially non-magnetic in the annealed condition, and can only be hardened by cold working. Titanium is added to suppress grain boundary chromium carbide precipitation, and to reduce susceptibility to intergranular corrosion, through the formation of very stable titanium carbide [3].

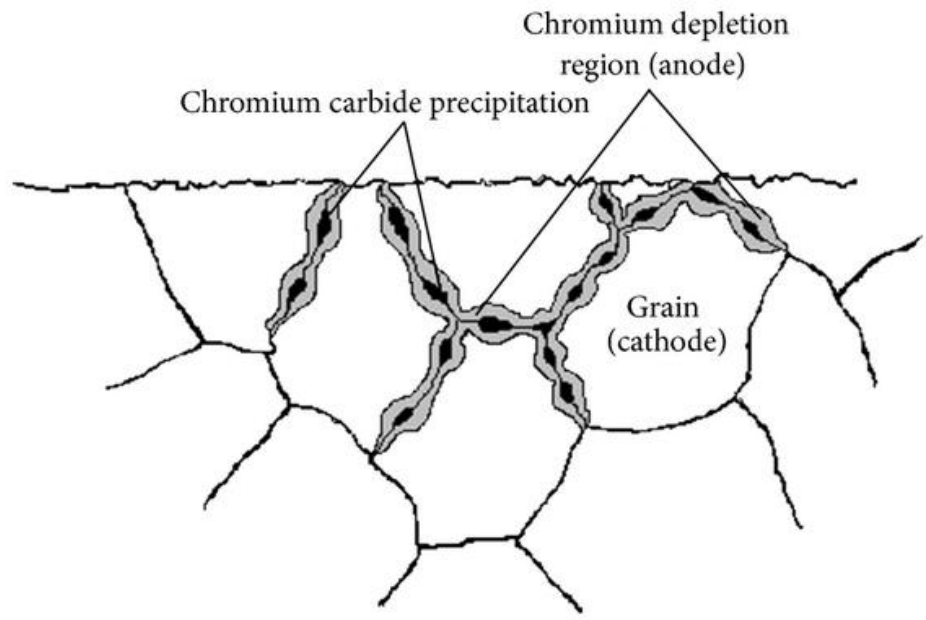

Fig. 1. Schematic representation of the carbide precipitation at grain boundaries in austenitic stainless steel [1]

Before shaping the component into a desired geometry, steels often undergoes a thermomechanical processing during which materials change certain properties. Cold deformations are assumed to alter the properties of steels through increasing dislocation density which apart from its effect on mechanical properties, may help in accelerating the diffusion mechanism, phase transformation, lowering the activation energy and free energy for faster nucleation [2].

There have been contradictory remarks in the literature about the net influence of deformation on the sensitization kinetics of stainless steels. It was studied by Singh and Li $[2,3]$, who reported the lower corrosion of strained material compared to that of annealed. On the other hand Zhao [4] observed higher resistance of the unstrained material. One reason of such conflicting results could be the consideration of low level of deformations only. Consequently, the need was felt to investigate the sensitization and intergranular corrosion behaviour of stainless steel with wide range of deformation.

The present paper reports the results of various deformation levels on intergranular corrosion and the attempt has been made to establish the correlation corrosion rates with sensitization time and degree of cold work. 


\section{MATERIAL}

The material that was investigated was the commercially available X6CrNiTi18-10 (1.4541, AISI 321) stainless steel. The chemical composition of the investigated material, which was determined by optical emission spectroscopy, is shown in Table 1. The samples provided were in a supersaturated state.

Table 1. Chemical composition of the X6CrNiTi18-10 steel, wt.\%

\begin{tabular}{|c|c|c|c|c|c|c|c|}
\hline$\% \mathrm{C}$ & $\% \mathrm{Cr}$ & $\% \mathrm{Ni}$ & $\% \mathrm{Mn}$ & $\% \mathrm{P}$ & $\% \mathrm{Si}$ & $\% \mathrm{~S}$ & $\% \mathrm{Ti}$ \\
\hline 0.12 & 17.9 & 9.6 & 1.50 & 0.014 & 0.016 & 0.016 & 0.58 \\
\hline
\end{tabular}

The starting material was in the form of steel strips, thickness $\mathrm{g}=3 \mathrm{~mm}$ and width $\mathrm{b}=$ $100 \mathrm{~mm}$. These strips were then cold rolled with various degrees: $5,10,15$ and maximum $40 \%$. Samples of size: $100 \times 20 \times 3 \mathrm{~mm}$ were cut from the deformed strips and 6 batches of samples were prepared, each batch containing: a sample without deformation, and cold worked samples of $5,10,15$ and $40 \%$, which were subjected to a sensitizing annealing at $700^{\circ} \mathrm{C}$ during : 5 minutes, 30 minutes, $1 \mathrm{~h}, 4 \mathrm{~h}, 16 \mathrm{~h}$ and $32 \mathrm{~h}$. Sensitization is a terminology used to describe the precipitation of carbides at grain boundaries of alloys during hightemperature exposure. The essence of sensitization is that the rate of attack of austenitic stainless steels under intergranular attack conditions is extremely sensitive to the carbides precipitated in the 500 to $800^{\circ} \mathrm{C}$ temperature range.

After the heat treatment sensitizing to intergranular corrosion, the samples were cooled in air. Two dimensions of samples were prepared to assess the intensity of intergranular corrosion:

a) $20 \times 20 \times 3 \mathrm{~mm}$ samples were used for the weight loss test by boiling in $\mathrm{HNO}_{3}$ (Huey test), b) metallographic samples were made on $10 \times 20 \times 3 \mathrm{~mm}$ samples and after boiling in the Huey reagent, observations were made on optical and electron transmission and scanning microscopes.

Huey test was aimed at determining the intensity of intergranular corrosion by measuring the loss of mass during boiling in $\mathrm{HNO}_{3}$. Boiling consisted of 3 periods of 40 hours each with each exchange of acid after boiling. Before weighing, the samples were thoroughly rinsed in water and the corrosion products were removed with a soft rubber. After drying, the samples were weighed with an accuracy of $0.0001 \mathrm{~g}$.

\section{EXPERIMENTAL PROCEDURES}

Optical and electron transmission (TEM) microscopes were used to examine etched structures after cold work and after sensitization. Microscopic images were recorded using the inverted metallographic microscope Nikon MA100 equipped with the ERC5s digital camera and the ZEN 2011 archiving program. After boiling in the Huey reagent, observations were made on optical and scanning JSM 5600 JEOL microscope (SEM).

The specimens for transmission electron microscopy (TEM) were sliced into $0.35 \mathrm{~mm}$ thick discs while being kerosene cooled. The discs were subsequently ground down to a thickness of 40-50 $\mu \mathrm{m}$. These specimens were finally electropolished in a twin-jet and stored 
in ethanol and finally examined in a Tesla BS-540 transmission electron microscope at an operating voltage of $120 \mathrm{kV}$.

The Huey test (EN-ISO 3651-1. Determination of resistance to intergranular corrosion of stainless steels-Part 1: Austenitic and ferritic-austenitic (duplex) stainless steels-Corrosion test in nitric acid medium by measurement of loss in mass ) [5] was used, consisting of boiling in concentrated $\mathrm{HNO}_{3}$ (nitric acid) at $95^{\circ} \mathrm{C}$ for three periods of time, each 40 hours. This test can generate intergranular corrosion in the austenitic steel. Before immersing the test specimens in nitric acid, they were well degreased with acetone solution and weighed to the fourth point of decimal (grams). After each test period the specimens were cleaned and weighed. The corrosion rates were obtained by using the formula (1) and are reported in $\left(\mathrm{g} \times \mathrm{m}^{-2} \times \mathrm{h}^{-1}\right)$.

\section{RESULTS AND DISCUSSION}

Corrosion losses of sample mass after each boiling cycle are presented in Table 2.

Table 2. Mass losses of samples after boiling in $\mathrm{HNO}_{3}$ during 40, 80 and 120 hours

\begin{tabular}{|l|l|c|c|c||c|c|c|}
\hline Lp. & $\begin{array}{l}\text { Time of } \\
\text { sensitization }\end{array}$ & \multicolumn{2}{|c||}{$\begin{array}{l}\text { After solution heat treatment, } \\
\text { State supersaturated }\end{array}$} & \multicolumn{3}{c|}{ Cold work 5\% } \\
\hline & & \multicolumn{3}{l}{$\begin{array}{l}\text { Weight loss of the sample in } \\
\text { grams after boiling in } \mathrm{HNO}_{3} \\
\text { at the time: }\end{array}$} & \multicolumn{2}{l|}{$\begin{array}{l}\text { Weight loss of the sample in } \\
\text { grams after boiling in } \mathrm{HNO}_{3} \\
\text { at the time: }\end{array}$} \\
\hline & & $40 \mathrm{~h}$ & $80 \mathrm{~h}$ & $120 \mathrm{~h}$ & $40 \mathrm{~h}$ & $80 \mathrm{~h}$ & $120 \mathrm{~h}$ \\
\hline & & $G_{1}$ & $G_{2}$ & $G_{3}$ & $G_{1}$ & $G_{2}$ & $G_{3}$ \\
\hline 1. & $5 \mathrm{~min}$. & 0.0101 & 0.0212 & 0.0473 & 0.0108 & 0.0255 & 0.0533 \\
\hline 2. & $30 \mathrm{~min}$. & 0.0185 & 0.1069 & 0.2671 & 0.0109 & 0.0273 & 0.0783 \\
\hline 3. & $1 \mathrm{~h}$ & 0.0216 & 0.1506 & 0.3005 & 0.0138 & 0.0303 & 0.0770 \\
\hline 4. & $4 \mathrm{~h}$ & 0.0219 & 0.0795 & 0.2053 & 0.0128 & 0.0307 & 0.0510 \\
\hline 5. & $16 \mathrm{~h}$ & 0.0152 & 0.0305 & 0.0406 & 0.0123 & 0.0239 & 0.0443 \\
\hline 6. & $32 \mathrm{~h}$ & 0.0170 & 0.0433 & 0.0473 & 0.0129 & 0.0248 & 0.0520 \\
\hline
\end{tabular}

continued Table 2.

\begin{tabular}{|c|c|c|c|c|c|c|c|c|c|c|}
\hline \multirow{3}{*}{ No. } & \multirow{3}{*}{$\begin{array}{l}\text { Time of } \\
\text { sensiti- } \\
\text { zation }\end{array}$} & \multicolumn{3}{|c|}{ Cold work $10 \%$} & \multicolumn{3}{|c|}{ Cold work $15 \%$} & \multicolumn{3}{|c|}{ Cold work $40 \%$} \\
\hline & & \multicolumn{3}{|c|}{$\begin{array}{l}\text { Weight loss of the sample in } \\
\text { grams after boiling in } \mathrm{HNO}_{3} \\
\text { at the time: }\end{array}$} & \multicolumn{3}{|c|}{$\begin{array}{l}\text { Weight loss of the sample in } \\
\text { grams after boiling in } \mathrm{HNO}_{3} \\
\text { at the time: }\end{array}$} & \multicolumn{3}{|c|}{$\begin{array}{l}\text { Weight loss of the sample in } \\
\text { grams after boiling in } \mathrm{HNO}_{3} \\
\text { at the time: }\end{array}$} \\
\hline & & $40 \mathrm{~h}$ & $80 \mathrm{~h}$ & $120 \mathrm{~h}$ & $40 \mathrm{~h}$ & $80 \mathrm{~h}$ & $120 \mathrm{~h}$ & $40 \mathrm{~h}$ & $80 \mathrm{~h}$ & $120 \mathrm{~h}$ \\
\hline & & $G_{1}$ & $G_{2}$ & $G_{3}$ & $G_{1}$ & $G_{2}$ & $G_{3}$ & $G_{1}$ & $G_{2}$ & $G_{3}$ \\
\hline 1. & 5 min. & 0.0103 & 0.0205 & 0.0395 & 0.0103 & 0.0167 & 0.0388 & 0.0103 & 0.0198 & 0.0306 \\
\hline 2. & $30 \mathrm{~min}$. & 0.0115 & 0.0194 & 0.0310 & 0.0111 & 0.0152 & 0.0372 & 0.0020 & 0.0102 & 0.0341 \\
\hline 3. & $1 \mathrm{~h}$ & 0.0101 & 0.0193 & 0.0332 & 0.0078 & 0.0158 & 0.0364 & 0.0099 & 0.0175 & 0.0239 \\
\hline 4. & $4 \mathrm{~h}$ & 0.0114 & 0.0183 & 0.0378 & 0.0096 & 0.0147 & 0.0240 & 0.0068 & 0.0153 & 0.0222 \\
\hline 5. & $16 \mathrm{~h}$ & 0.0125 & 0.0226 & 0.0359 & 0.0116 & 0.0210 & 0.0458 & 0.0123 & 0.0228 & 0.0338 \\
\hline 6. & $32 \mathrm{~h}$ & 0.0132 & 0.0203 & 0.0427 & 0.0171 & 0.0249 & 0.0403 & 0.0126 & 0.0246 & 0.0257 \\
\hline
\end{tabular}


Assessment of the intensity of intergranular corrosion after boiling test in $\mathrm{HNO}_{3}$ was based on determining the average corrosion rate $V_{\text {cor }}$ according to PN-EN ISO 3651-1 [5]:

$$
V_{\text {cor }}=\frac{10000 \mathrm{~m}}{S t}
$$

where:

$t$ - time of boiling in the solution (hours),

$S$ - surface area of the test sample $\left(\mathrm{cm}^{2}\right)$,

$m$ - the average loss in mass of the sample during the test $(\mathrm{g})$,

$m=G_{1}-G_{2}$

where:

$G_{1}$ - weight of the sample before boiling (g),

$G_{2}$ - sample weight after boiling $(\mathrm{g})$.

The corrosion rate after each cooking cycle and the average corrosion speed are shown in Table 3.

Table 3. Corrosion rate V1, V2 and V3 after the boiling cycle during 40, 80 and 120 hours and the average arithmetic corrosion rate Vav, $(g \times m-2 \times h-1)$

\begin{tabular}{|c|c|c|c|c|c|c|c|c|c|}
\hline \multirow[t]{3}{*}{ No. } & \multirow{2}{*}{$\begin{array}{l}\text { Time } \\
\text { of } \\
\text { sensiti- } \\
\text { zation }\end{array}$} & \multicolumn{4}{|c|}{$\begin{array}{l}\text { After solution heat treatment, } \\
\text { State supersaturated }\end{array}$} & \multicolumn{4}{|c|}{ Cold work 5\% } \\
\hline & & \multicolumn{4}{|c|}{$\begin{array}{l}\text { Corrosion rate, } \times 10 \\
V_{a v},\left(\mathrm{~g} \times \mathrm{m}^{-2} \times \mathrm{h}^{-1}\right)\end{array}$} & \multicolumn{4}{|c|}{$\begin{array}{l}\text { Corrosion rate, } \times 10 \\
V_{a v},\left(\mathrm{~g} \times \mathrm{m}^{-2} \times \mathrm{h}^{-1}\right)\end{array}$} \\
\hline & & $V_{1}$ & $V_{2}$ & $V_{3}$ & $V_{a v}$ & $V_{1}$ & $V_{2}$ & $V_{3}$ & $V_{a v}$ \\
\hline 1. & $5 \mathrm{~min}$. & 2.4 & 5.3 & 11.6 & 6.4 & 2.6 & 6.3 & 13.0 & 7.3 \\
\hline 2. & $30 \mathrm{~min}$. & 4.4 & 25.7 & 64.3 & 31.5 & 2.7 & 6.7 & 19.2 & 9.5 \\
\hline 3. & $1 \mathrm{~h}$ & 5.3 & 36.8 & 73.6 & 38.6 & 3.4 & 7.2 & 19.1 & 9.9 \\
\hline 4. & $4 \mathrm{~h}$ & 5.1 & 18.7 & 48.3 & 24.0 & 3.0 & 7.2 & 12.0 & 7.3 \\
\hline 5. & $16 \mathrm{~h}$ & 3.6 & 7.3 & 9.7 & 6.5 & 2.8 & 5.8 & 10.8 & 6.5 \\
\hline 6. & $32 \mathrm{~h}$ & 4.1 & 10.4 & 11.4 & 8.6 & 3.1 & 5.9 & 12.5 & 7.2 \\
\hline
\end{tabular}

continued Table 3.

\begin{tabular}{|c|c|c|c|c|c|c|c|c|c|c|c|c|c|}
\hline \multirow[t]{3}{*}{ No. } & \multirow{2}{*}{$\begin{array}{l}\text { Time of } \\
\text { sensiti- } \\
\text { zation }\end{array}$} & \multicolumn{4}{|c|}{ Cold work $10 \%$} & \multicolumn{4}{|c|}{ Cold work $15 \%$} & \multicolumn{4}{|c|}{ Cold work $40 \%$} \\
\hline & & \multicolumn{4}{|c|}{$\begin{array}{c}\text { Corrosion rate, } \times 10 \\
V_{a v},\left(\mathrm{~g} \times \mathrm{m}^{-2} \times \mathrm{h}^{-1}\right)\end{array}$} & \multicolumn{4}{|c|}{$\begin{array}{l}\text { Corrosion rate, } \times 10 \\
V_{a v},\left(\mathrm{~g} \times \mathrm{m}^{-2} \times \mathrm{h}^{-1}\right)\end{array}$} & \multicolumn{4}{|c|}{$\begin{array}{c}\text { Corrosion rate, } \times 10 \\
V_{a v},\left(\mathrm{~g} \times \mathrm{m}^{-2} \times \mathrm{h}^{-1}\right)\end{array}$} \\
\hline & & $V_{1}$ & $V_{2}$ & $V_{3}$ & $V_{a v .}$ & $V_{1}$ & $V_{2}$ & $V_{3}$ & $V_{a v .}$ & $V_{1}$ & $V_{2}$ & $V_{3}$ & $V_{a v}$ \\
\hline 1. & 5 min. & 2.4 & 4.9 & 9.4 & 5.6 & 2.4 & 4.0 & 9.3 & 5.2 & 2.6 & 5.0 & 7.8 & 5.1 \\
\hline 2. & $30 \mathrm{~min}$. & 2.7 & 4.7 & 7.4 & 4.9 & & & & & 2.0 & 3.0 & 8.7 & 4.6 \\
\hline 3. & $1 \mathrm{~h}$ & 2.4 & 4.8 & 8.1 & 5.1 & 1.9 & 3.8 & 8.9 & 4.9 & 2.5 & 4.4 & 6.1 & 4.3 \\
\hline 4. & $4 \mathrm{~h}$ & 2.8 & 4.4 & 9.2 & 5.5 & 2.3 & 3.6 & 5.9 & 3.9 & 2.2 & 3.9 & 5.7 & 3.9 \\
\hline 5. & $16 \mathrm{~h}$ & 3.0 & 5.4 & 8.6 & 5.7 & 2.8 & 5.0 & 10.1 & 5.4 & 3.1 & 5.8 & 8.6 & 5.0 \\
\hline 6. & $32 \mathrm{~h}$ & 3.2 & 4.9 & 10.4 & 6.2 & 4.1 & 5.9 & 9.7 & 6.6 & 3.2 & 6.2 & 6.5 & 5.3 \\
\hline
\end{tabular}


The dependence of changes in the intensity of intergranular corrosion from the time of sensitization and degree of cold work are shown in Figures 2 and 3.

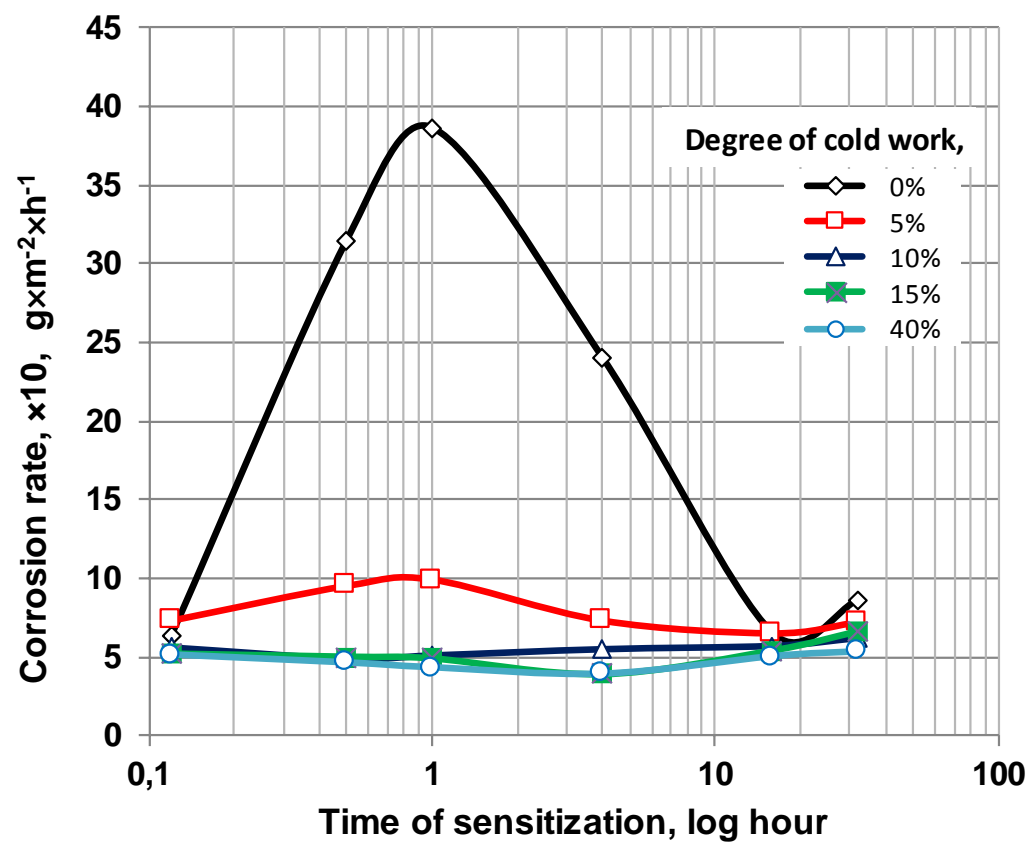

a)

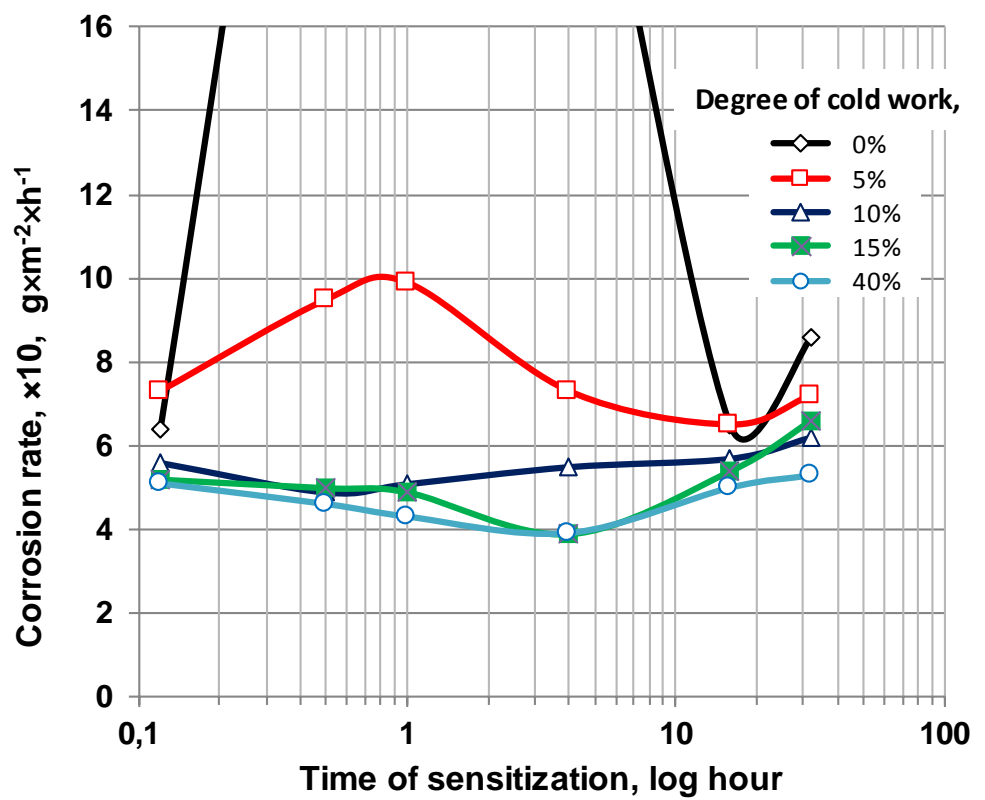

b)

Fig. 2. Dependence of the intergranular corrosion rate in $\mathrm{X} 6 \mathrm{CrNiTi18-10}$ steel on time of sensitization for different degrees of cold work a), b) enlargement of a part of Figure $2 a$ 


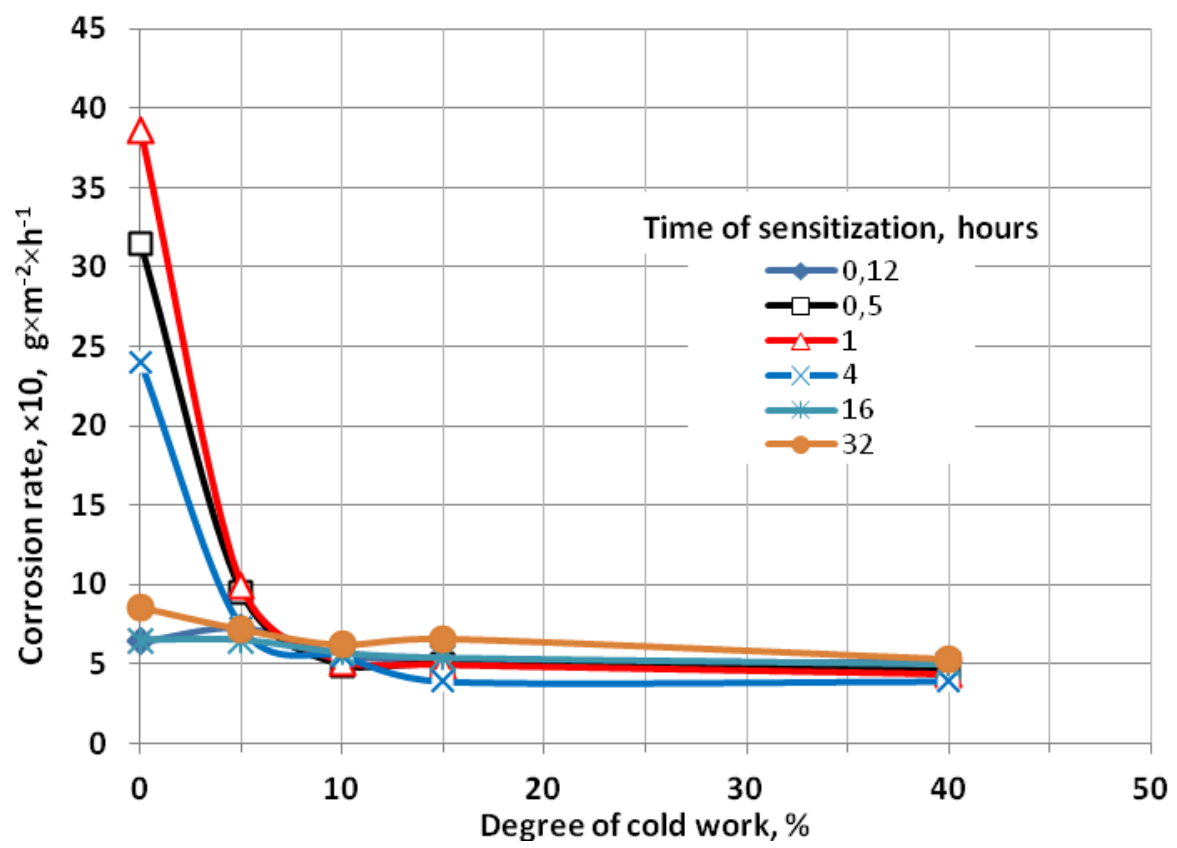

Fig. 3. Dependence of the intergranular corrosion rate in X6CrNiTi18-10 steel on degree of cold work for different time of sensitization

\section{MICROSTRUCTURAL ANALYSIS}

Light optical microscopy and transmission/scanning electron microscopy micrographs of the investigated steel were taken after cold deformation and sensitization. The microstructure of the X6CrNiTi18-10 steel is shown in Figures 4-8.

The microstructure of the undeformed stainless steel samples (Fig. 4a), observed by an optical microscope, was austenitic. Metallographic investigation revealed austenitic polygonal grain features intersected with annealing twins and in Fig. $4 \mathrm{~b}$ slips produced by cold working $5 \%$.

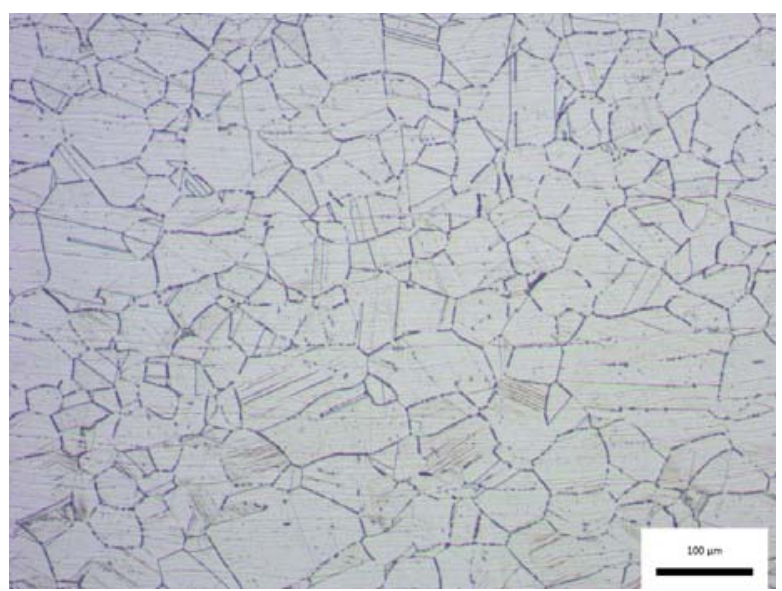

a)

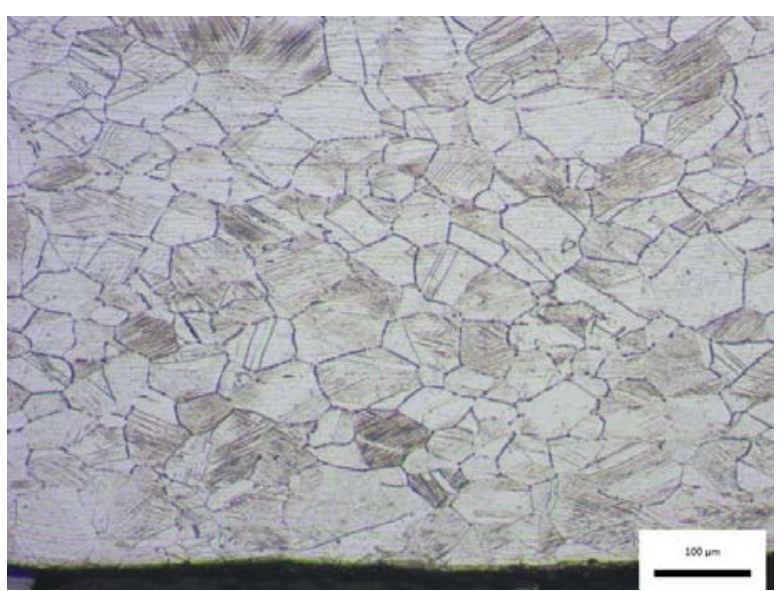

b) 


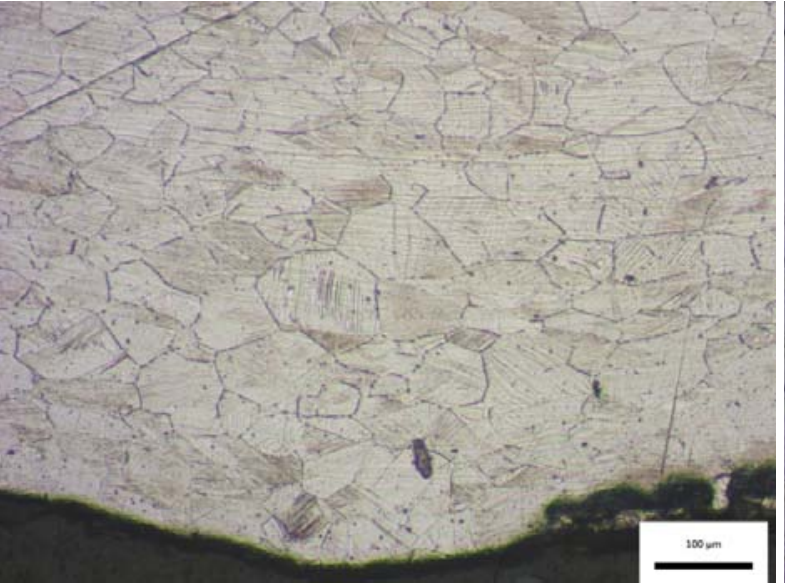

c)

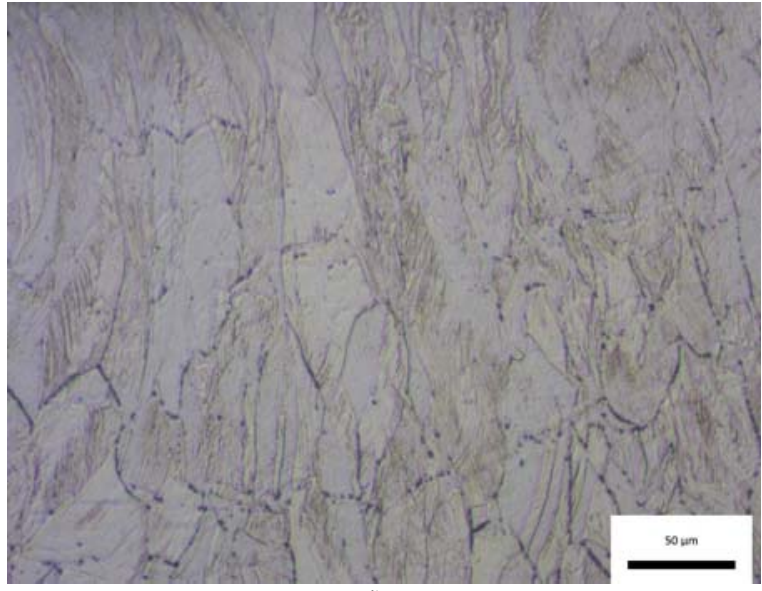

d)

Fig. 4. Microstructure of $X 6 \mathrm{CrNiTi18-10} \mathrm{steel,} \mathrm{a)} \mathrm{supersaturated} \mathrm{state,} \mathrm{no} \mathrm{deformation,} \mathrm{b)} \mathrm{cold} \mathrm{work} \mathrm{5 \% ,} \mathrm{c)} \mathrm{cold}$ work $15 \%$, d) cold work $40 \%$

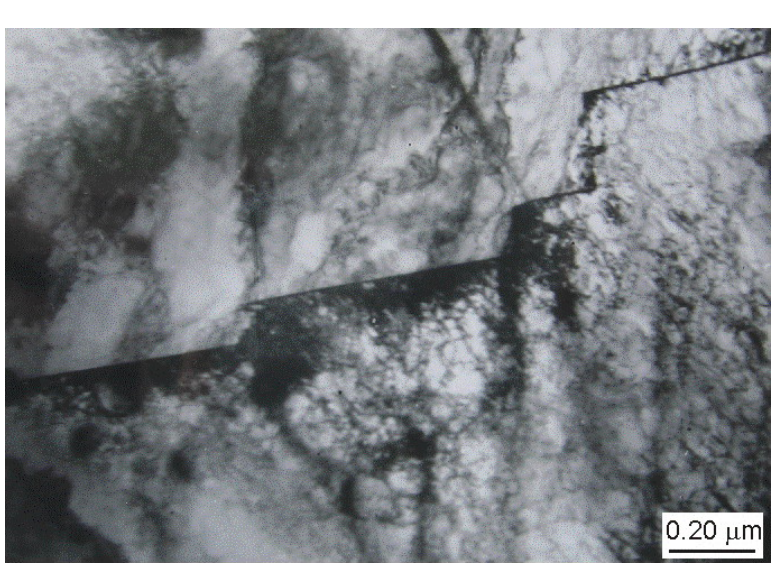

a)

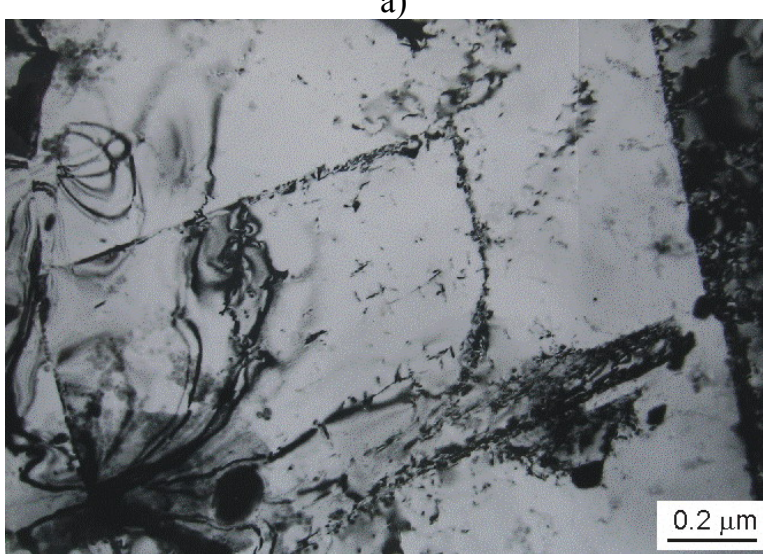

c)

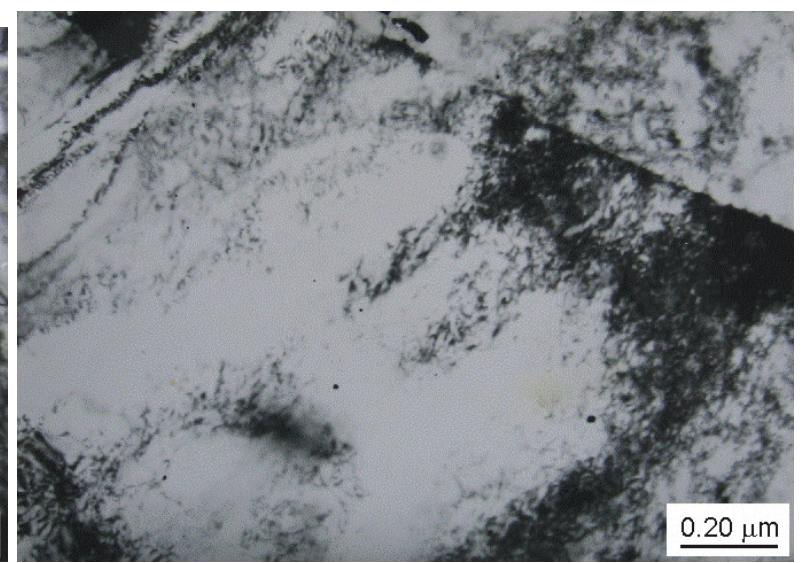

b)

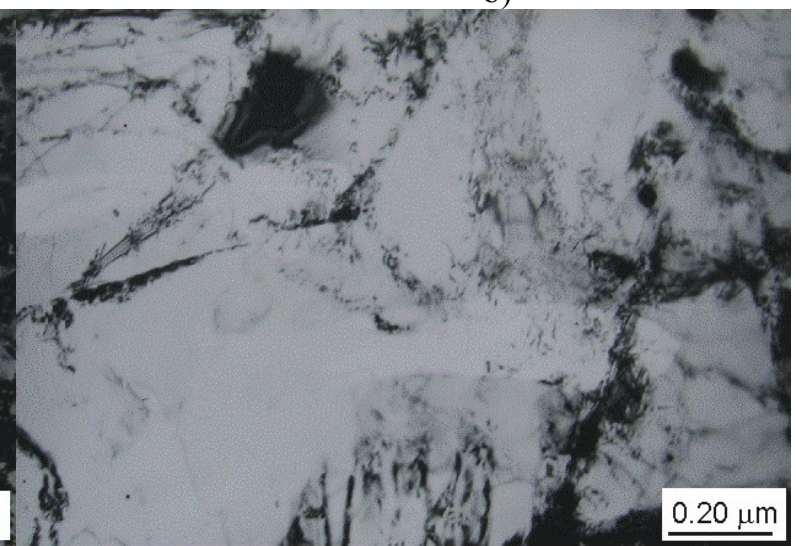

d)

Fig. 5. Microstructure of X6CrNiTi18-10 steel after cold work, a) 40\%, b) 15\%, c) 10\%, d) 5\% and sensitization at $700^{\circ} \mathrm{C}$ for $1 \mathrm{~h}$. TEM. Thin foils 


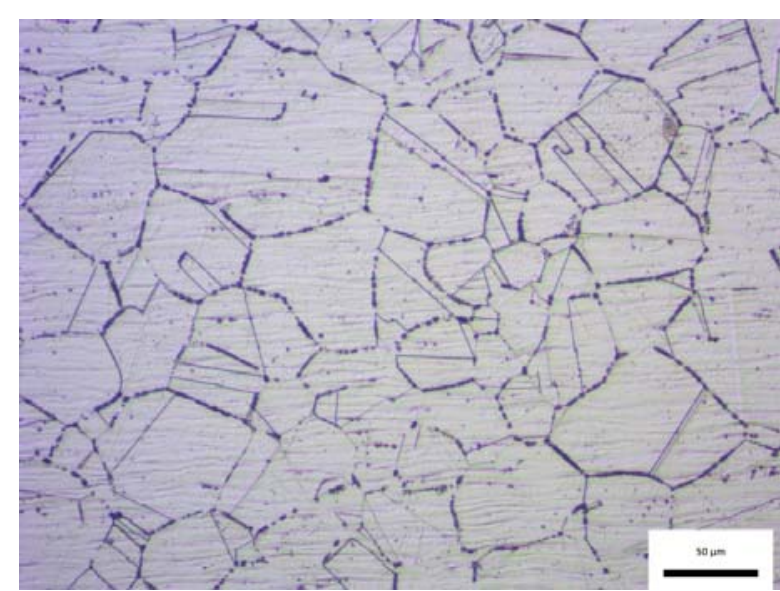

a)

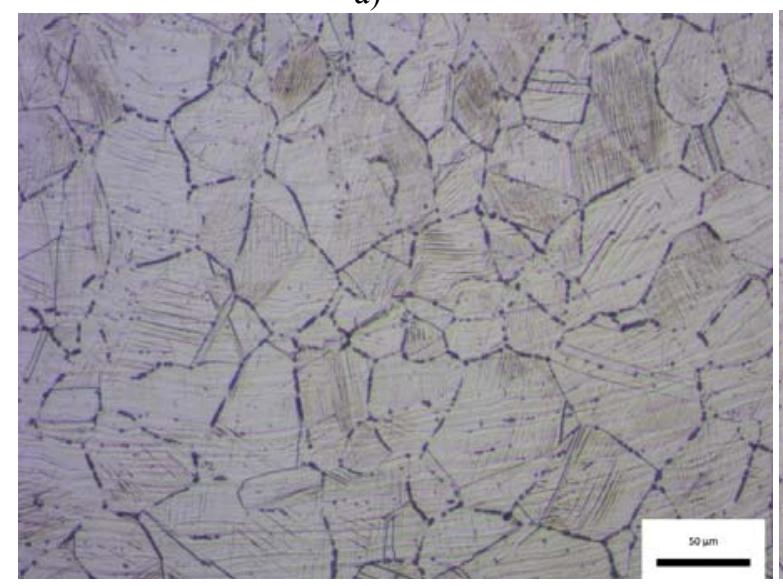

c)

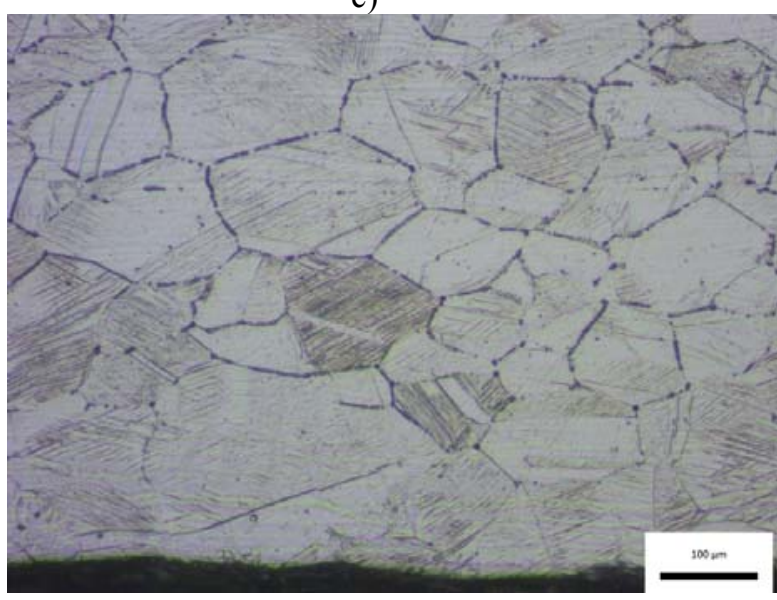

e)

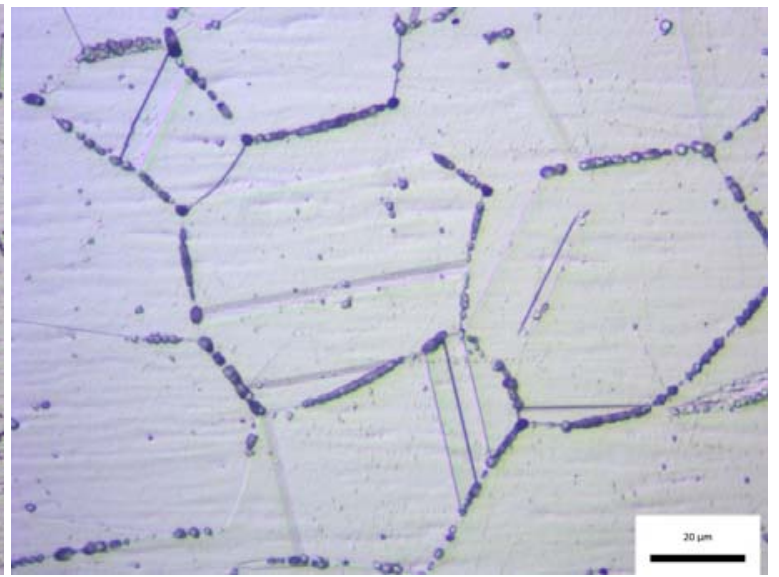

b)

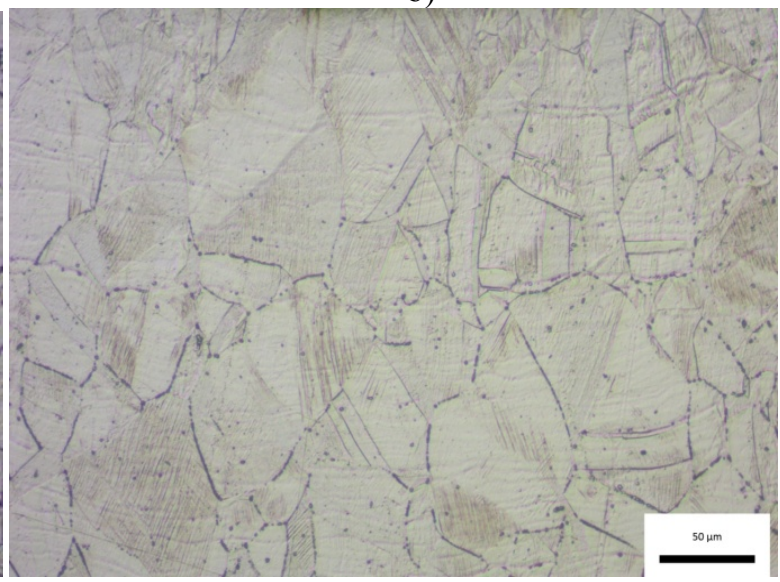

d)

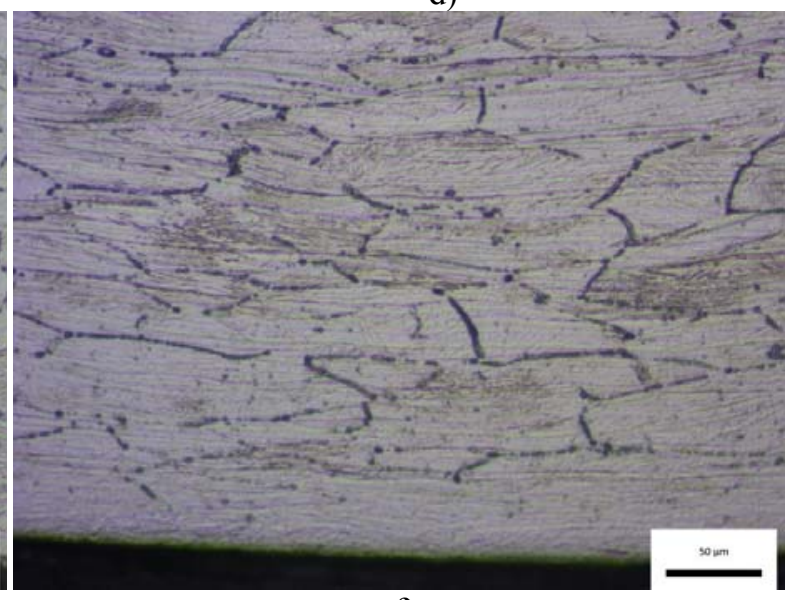

f)

Fig. 6. Microstructure of $X 6 \mathrm{CrNiTi18}-10$ steel after sensitization at $\left.700^{\circ} \mathrm{C} / 1 \mathrm{~h}, \mathrm{a}, \mathrm{b}\right)$ cold work $0 \%$, c) cold work $5 \%$, d) cold work $10 \%$, e) cold work $15 \%$, f) cold work $40 \%$ 


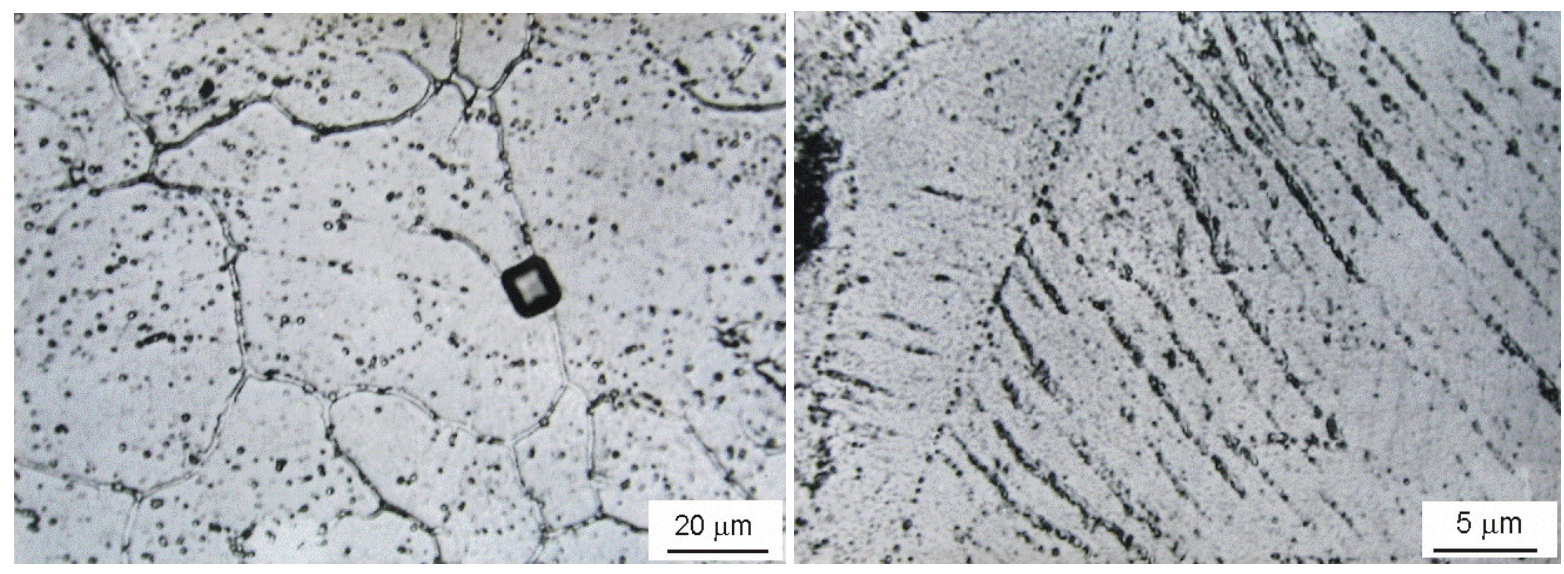

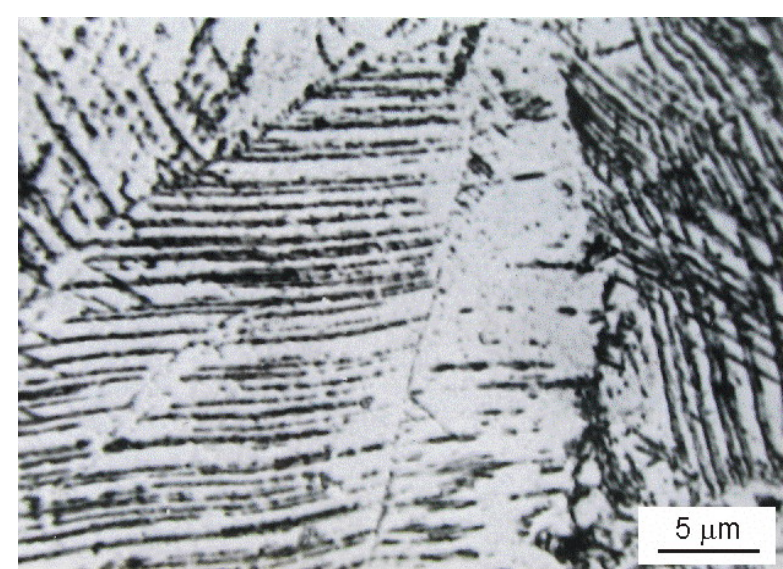

a)

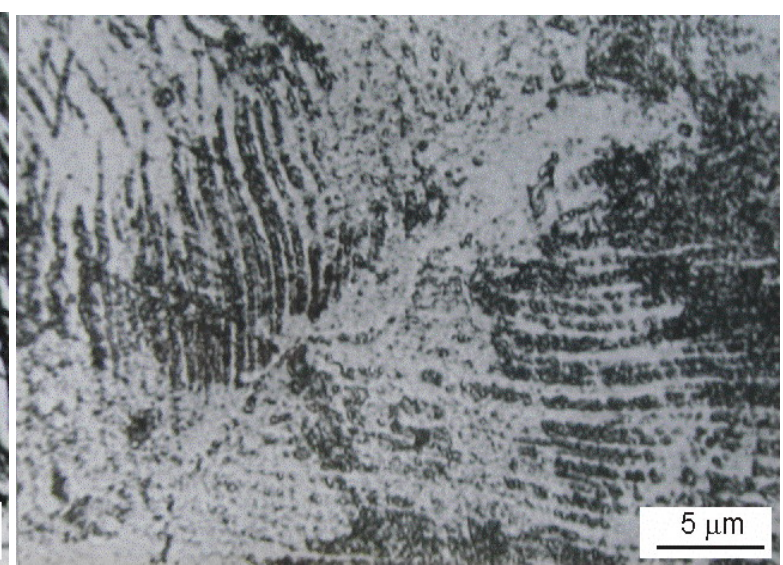

b)

Fig. 7. Microstructure of $X 6 \mathrm{CrNiTi} 18-10$ steel after sensitization at $700^{\circ} \mathrm{C}$, a) 32 hours, cold work $10 \%$, b) 4 hours, cold work $40 \%$, b) 16 hours, cold work $40 \%$, b) 32 hours, cold work $40 \%$

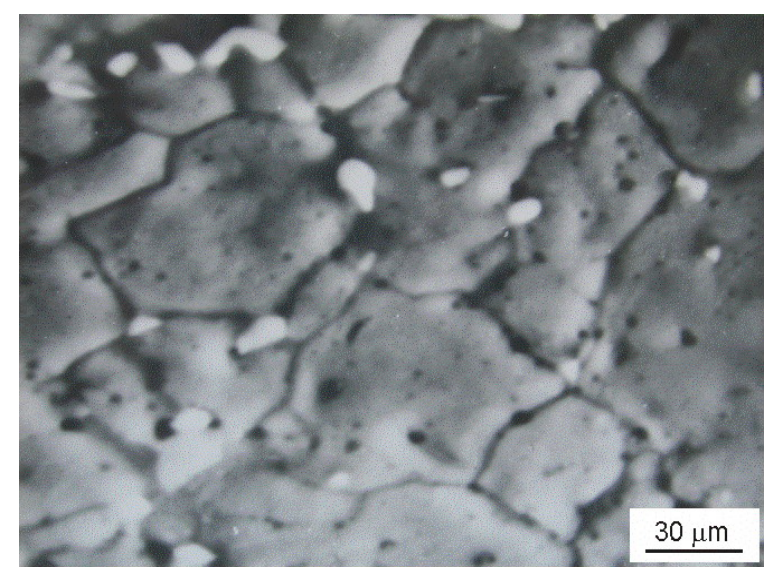

a)

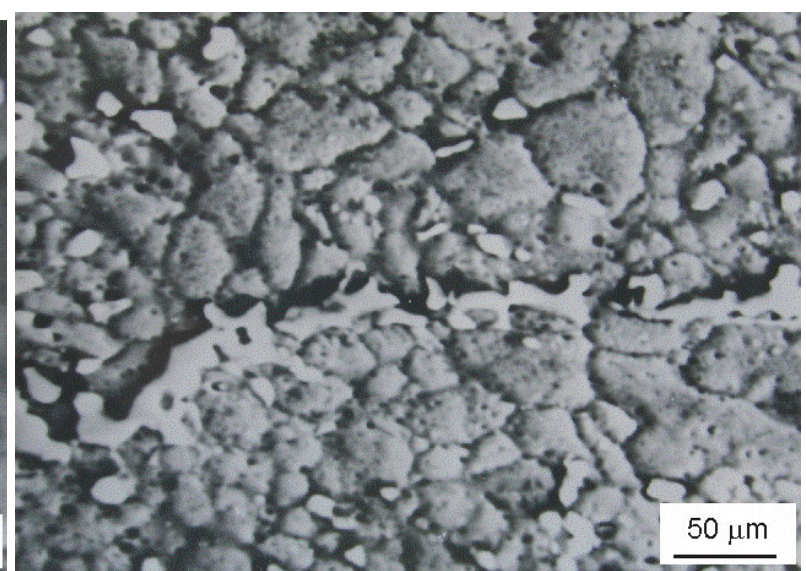

b)

Fig. 8. Microstructure of the surface of $\mathrm{X} 6 \mathrm{CrNiTi} 18-10$ steel after sensitization at $700^{\circ} \mathrm{C} 1$ hour and boiling in HNO3 for, a) 40 hours, b) 80 hours. SEM

An attempt to boil in $\mathrm{HNO}_{3}$ as well as microscopic observations showed that the deformation (starting from just 5\% small crushing forces) very clearly reduces the susceptibility of X6CrNiTi18-10 steel to intergranular corrosion (Fig. 2,3). This steel, in the supersaturated state, intensely corrodes intercrystalline, while the deformation of $5 \%$, especially $10 \%, 15 \%$ and maximum $40 \%$, significantly reduces the tendency of this steel to intercrystalline corrosion (Fig. 2,3). 
For X6CrNiTi18-10 steel in the supersaturated state, the most intense corrosion occurs after heating at $700^{\circ} \mathrm{C}$ from 30 minutes to 4 hours. After prolonged heating periods at a temperature of $700^{\circ} \mathrm{C}$, the intensity of corrosion decreases. This phenomenon may be a confirmation of the validity of the theory of depletion of chromium of grain boundaries, which explains the sensitization of austenitic steels to intergranular corrosion [6-8].

The Fig. 2 and Fig. 3 show that as the heating time increases about 1 hour for steel in the supersaturated state, the intensity of corrosion decreases.

In this first stage of annealing (up to about 1 hour), due to the precipitation of the carbide phase at the boundaries of austenite grains, the process of depleting in chromium the border regions of the grain takes place, thus reducing their stability.

In the second stage, for longer boiling times, there is diffusion of chromium atoms from the internal grain regions towards the border zones, which were previously depleted in chromium. These zones, after the time required for the diffusion of chromium atoms to the grain boundaries, are again enriched with chromium, and when its content reaches $12.5 \%$, they regain stability and thus become resistant to the corrosive effects of the environment [913].

Cold work of X6CrNiTi18-10 steel very clearly improves its resistance to intergranular corrosion. With increasing deformation, corrosion resistance of this steel is also gradually increasing (Fig. 2,3). The obtained results are consistent with the general view that cold work before sensitization, reduces the intensity of intergranular corrosion [13-15]. This is due to the deformation of the structure (twins, slip bands, stacking errors, grain refinement) (Fig. 5-7). All these places are similar to the grain boundaries, in places of the privileged precipitation of carbide phases, as a result of which the concentration of the separated phases on the grain boundaries is smaller, and thus the corrosion rate decreases (Fig. 8). Also the composition of steel has a large influence on the tendency of steel to intercrystalline corrosion in the case of the addition of titanium [16-17]. Titanium reduces the formation rate of $\mathrm{M}_{23} \mathrm{C}_{6}$ carbides to a very large extent, because a significant part of the carbon is bound in titanium carbonitride $\operatorname{Ti}(\mathrm{CN})$.

\section{CONCLUSIONS}

The effect of prior cold deformation and sensitization time on intergranular corrosion resistance in X6CrNiTi18-10 austenitic stainless steel were investigated. The following conclusions were drawn:

1. Intergranular corrosion of undeformed specimens increases with sensitization time of exposure up to 1 hour. Sensitization of the X6CrNiTi18-10 steels accelerated the precipitation of the carbides which were also detected on the grain boundaries and in the austenitic matrix in the case of cold working samples.

2. High deformations reduces rate of intergranular corrosion. After $\sim 40 \%$ cold working, even the sites inside the grain matrix have high energy, and carbides can nucleate there easily. 


\section{REFERENCES}

1. Haraszti F. and Kovacs T.: IOP Conf. Series: Materials Science and Engineering. 175 (2017) (http://iopscience.iop.org/1757-899X/175/1/012048).

2. Singh R., Dey P.D., Kumar A., Das S.K., Kumar R. and Chattoraj I.: Intergranular corrosion of deformed SS304. NSCP (2001) 29-33.

3. Li S.X., He Y., Yu S., Zhang P.: Evaluation of the effect of grain size on chromium carbide precipitation and intergranular corrosion of 316L stainless steel. Corrosion Science 66 (2013) 211-216.

4. Zhao H., Zhang Z., Zhang H., Hu J., Li J.: Effect of aging time on intergranular corrosion behavior of a newly developed LDX 2404 lean duplex stainless steel. Journal of Alloys and Compounds 672 (2016) 147-154.

5. PN-EN ISO 3651-1:2004. Oznaczanie odporności na korozję międzykrystaliczną stali odpornych na korozję. Część 1: Stale odporne na korozję austenityczne i ferrytyczno-austenityczne (duplex). Badanie korozyjne w środowisku kwasu azotowego (V) przez pomiar ubytku masy (próba Hueya).

6. Luo H., Sub H., Yinga G., Dong C., Li X.: Effect of cold deformation on the electrochemical behaviour of $304 \mathrm{~L}$ stainless steel in contaminated sulfuric acid environment. Applied Surface Science 425 (2017) 628-638.

7. Zhang L., Szpunar L., Basu R., Dong J., Zhang M.: Influence of cold deformation on the corrosion behavior of Ni-Fe-Cr-alloy 028. Journal of Alloys and Compounds 616 (2014) 235242.

8. Terada M., Saiki M., Costa I., Padilha A.F.: Microstructure and intergranular corrosion of the austenitic stainless steel 1.4970. Journal of Nuclear Materials 358 (2006) 40-46.

9. Kosec L., Savli S., Kozuh S., et al.: Transformation of austenite during isothermal annealing at $600-900^{\circ} \mathrm{C}$ for heat-resistant stainless steel. Journal of Alloys and Compounds 567 (2013) 59-64.

10. Sahlaoui H., Sidhom H., Philibert J.: Prediction of chromium depleted-zone evolution during aging of Ni-Cr-Fe alloys. Acta Materialia 50 (2002) 1383-1392.

11. Li J., Liang T., Wang C., Guo T.: Influence of sensitization on passive films in AISI 2205 duplex stainless steel. Journal of Alloys and Compounds 658 (2016) 657-662.

12. Zhang Z., Zhao H, Zhang H., Yu Z., Hu J., He L., Li J.: Effect of isothermal aging on the pitting corrosion resistance of LDX 2404 duplex stainless steel based on electrochemical detection. Corrosion Science 93 (2015) 120-125.

13. Zhang W., Frankel G.S.: Transitions between pitting and intergranular corrosion in AA2024. Electrochimica Acta 48 (2003) 1193-1210.

14. Gorhe D.D., Raja K.S., Namjoshi S.A., Radmilovic V., Tolly A., Jones D.A.: Electrochemical methods to detect susceptibility of Ni-Cr-Mo-W alloy to intergranular corrosion. Metallurgical and Materials Transactions A 36 (2005) 1153-1167.

15. Zhang Z, Zhang H, Han D, He L., Jiang Y., Li J.: Precipitation evolution in duplex stainless steel during isothermal aging at $700^{\circ} \mathrm{C}$. Materials Science and Technology 30 (2014) 451-457.

16. Arutunow A., Darowicki K.: DEIS assessment of AISI 304 stainless steel dissolution process in conditions of intergranular corrosion. Electrochimica Acta 53 (2008) 4387-4395.

17. Arutunow A., Darowicki K.: DEIS evaluation of the relative effective surface area of AISI 304 stainless steel dissolution process in conditions of intergranular corrosion. Electrochimica Acta 54 (2009) 1034-1041. 